\section{SOMETHING OLD, SOMETHING NEW}

In this issue we carry a Glossary of public health history that may prove controversial; debate is welcome. Speaker's Corner addresses the challenge of providing a systematic evidence base to tackle inequalities in health, something that becomes evermore pressing as the limitations of biomedical evaluation become apparent. This is reinforced by a rare contribution on social inequalities in health in the United States from Harvard. An optimistic note on public health aspects of housing provision for the homeless from Glasgow reminds us of how recently the concept of the "undeserving poor" has maintained its currency.

See pages $164,162,186,163$

On the environmental front, a metaanalysis of studies on individual consumption of chlorinated drinking water and bladder cancer finds a moderately high relative risk, but suggests that the attributable risk could be important.

See page 166

Healthy schools goes from strength to strength around the world, this time a report from Hong Kong in our Policy and Practice section, together with a report from Finland on the equity aspects of an increased supply of coronary operations.

See pages 174, 178

In Theory and Methods, we explore life table methods for quantitative impact assessment in chronic mortality, and report the use of a capture-recapture approach to estimate the lesbian population in Pennsylvania (about $2 \%$ ).

See pages 200, 207

Research findings this month describe the characteristics of neighbourhoods and people on cause specific mortality in a Finnish register, and look at the long term aspects of fruit, vegetables and antioxidants on the risk of adult cancer in the Boyd Orr cohort of 1937 to 1939 concluding that childhood fruit consumption may have a long term protective effect on cancer risk in adults. A report on early and late growth dynamics in adolescence suggests that catch up growth is associated with increased blood pressure; this from Brazil.

See pages $210,218,226$

An important letter on directly observed therapy (DOT) for TB patients underlines the important point that one size does not fit all. Book Reviews touch on the evidence debate, on spatial epidemiology, and on the relation between physical activity and psychological wellbeing.

See pages 231, 232

"All professions are conspiracies against the laity" (George Bernard-Shaw)

$\mathrm{T}$ he way in which professions acquire prestige, power and wealth is by taking unto themselves a body of knowledge and expertise and only relinquishing it in doses in exchange for payment. The creation of dependency is an intrinsic part of that process. In contrast, public health should share with the more enlightened types of psychotherapy the desire that individuals and communities should attain, maintain or develop self sufficiency and sustainability. The term empowerment currently enjoys a popular usage, but this itself can seem patronising if the natural state is the achievement of mastery over the environment by individuals and groups. Striking a style of practice that is respectful of people's strengths and the gifts that they bring to problem solving is the challenge to all public health practitioners and systems. 